\title{
Semantic memory, but not education or intelligence, moderates cognitive aging: a cross-sectional study
}

\author{
Laiss Bertola, ${ }^{1}$ (iD Rafaela T. Ávila, ${ }^{1}$ Maria Aparecida C. Bicalho, ${ }^{2}$ Leandro F. Malloy-Diniz ${ }^{1}$ \\ ${ }^{1}$ Departamento de Saúde Mental, Faculdade de Medicina, Universidade Federal de Minas Gerais (UFMG), Belo Horizonte, MG, Brazil. \\ ${ }^{2}$ Departamento de Clínica Médica, Faculdade de Medicina, UFMG, Belo Horizonte, MG, Brazil.
}

\begin{abstract}
Objective: Aging studies regularly assume that years of education are a protective factor for baseline cognition. In developing countries with specific sociocultural issues, this relationship may not work as expected, and an unmet need remains for alternative resilience factors. This study aimed to analyze different moderators for the relationship between aging and general cognition that could reflect better protective factors.

Methods: One hundred and fourteen Brazilian older adults, deemed healthy by global cognition, absence of psychiatric symptoms, or neurological history, participated in this cross-sectional study. Moderators for the relationship between age and global cognition included education, intelligence, and occupational factors. Semantic memory was added as a protective factor reflecting culturally acquired conceptual knowledge.

Results: As expected, age alone is a predictor of global cognitive scores; surprisingly, however, education, intelligence, and occupation were not moderators of the association. Semantic memory was a significant moderator $(p=0.007)$, indicating that knowledge acquired during life may be a protective factor.

Conclusion: In developing countries, the use of resilience factors based only on years of education may be misleading. Sociocultural issues influence the educational system and achievement and, consequently, affect the use of this simple measure. Resilience-factor studies should consider using crystallized abilities when studying populations with sociocultural particularities.
\end{abstract}

Keywords: Semantics; protective factors; cognitive aging; educational status; developing countries; aging

\section{Introduction}

According to prospective epidemiological data, developing countries are expected to harbor the majority of dementia cases by $2040 .{ }^{1}$ Countrywide prevalence studies performed to date in Brazil and Latin America demonstrate dementia rates similar or higher than those of the developed world. ${ }^{2,3}$ This points to a need for understanding the impact of social singularities on aging to promote more appropriate interventions.

Years of education have consistently been regarded as a protective factor of the cognitive aging process. ${ }^{4-6}$ Although years of schooling alone may accurately represent the cognitive impact of education in some countries and social groups, this assumption cannot be made for worldwide implementation.

Studies of ethnically and socioculturally diverse populations have shown that the crude number of reported years of schooling may not precisely represent the impact of the educational process. ${ }^{7-9}$ In developing countries with specific sociocultural issues, a reappraisal of this

Correspondence: Laiss Bertola, Av. Prof. Alfredo Balena, 190, sala 503, CEP 30130-100, Belo Horizonte, MG, Brazil.

E-mail: laissbertola@gmail.com

Submitted Sep 28 2018, accepted Dec 21 2018, Epub Apr 152019. assumption is particularly warranted. In the case of Brazil, two main social factors interact with the education process in older-adult cohorts. For most older adults, studying was necessary only to learn basic reading and writing; work was the economic priority, concurrently with a ruralbased lifestyle. Moreover, the quality of education and its policies oscillated more than expected over time, resulting in an actual literacy level that does not correspond to reported years of schooling. ${ }^{10}$

Nevertheless, years of education act as a large protecting factor. Crystallized cognition has been identified as another, since it can capture mature cognitive ability. ${ }^{11,12}$ Considering that semantic memory - a crystallized ability responsible for knowledge - increases as a result of cultural and occupational engagement and daily experience, ${ }^{5,13,14}$ we aimed to ascertain whether it would be a better moderator than years of education in a socioculturally diverse sample. We also considered other frequently used resilience factors, such as occupational attainment ${ }^{15}$ and intelligence ${ }^{16}$ as secondary objectives.

How to cite this article: Bertola L, Ávila RT, Bicalho MA, MalloyDiniz LF. Semantic memory, but not education or intelligence, moderates cognitive aging: a cross-sectional study. Braz J Psychiatry. 2019;41:535-539. http://dx.doi.org/10.1590/1516-4446-2018-0290 


\section{Methods}

\section{Participants and procedures}

The present study has a cross-sectional design. One hundred and fourteen healthy Portuguese-speaking Brazilian older adults, with a mean age of 72.69 years (standard deviation $[S D]=8.25$ ) and mean educational attainment of 7.78 years $(S D=5.50)$, were recruited on the basis of preserved general cognition, absence of current psychiatric symptoms, and absence of relevant neurological history. Active recruitment took place between the years 2014-2016, in an urban city; participants were sought in the community, from groups of government programs (i.e., public activity groups for older adults), retirees' groups (i.e., groups of retired workers from a public institution), and the public Unified Health System.

All participants underwent a clinical interview and neuropsychological assessment conducted by a neuropsychologist. The assessment comprised three stages: 1) a clinical interview designed to exclude subjects with psychiatric, neurological, or other self-reported diseases that have an impact on cognition; 2) a brief cognitive screening to exclude those subjects with pathological cognitive decline; and 3) a comprehensive neuropsychological assessment.

The Universidade Federal de Minas Gerais ethics committee approved this study, which was conducted in accordance with the ethical rules for human experimentation stated in the Declaration of Helsinki. All participants gave written consent.

The moderation model was built considering that age is usually associated with brain changes that reflect cognitive performance outcomes. ${ }^{17}$

The general cognition composite score was built using the Dementia Rating Scale (DRS) ${ }^{18}$ and the Frontal Assessment Battery (FAB), ${ }^{19}$ providing a brief assessment of all cognitive domains. An intelligence factor score was built using the Vocabulary subtest of the Wechsler Adult Intelligence Scale (WAIS)-III ${ }^{20}$ and the Raven Matrices. ${ }^{21}$ Occupation scores were based on the Brazilian Occupation Classification (Classificação Brasileira de Ocupações [CBO]) skill levels, and divided into low- or non-low-level occupations. ${ }^{22}$

Cognitive composite z scores of episodic memory, executive functions, and visuoconstruction abilities were computed to use as control variables for the semantic memory score. The episodic memory score was built from the Rey Auditory Verbal Learning Test (RAVLT) delay recall, total words, and recognition trial. ${ }^{23}$ The executive function score was built using the inverse digit $\operatorname{span}^{20}$ and the inhibitory control and cognitive flexibility measures of the Five Digit Test (FDT). ${ }^{24}$ The visuoconstruction score was built using the DRS constructional subscale and a copy of the simplified version of the Taylor Complex Figure (TCF). ${ }^{25}$ The processing speed score was based on the first part (number reading) of the FDT. All the tasks used have been psychometrically validated for use in Brazil and are adequate for assessment of older adults.

The semantic memory score was based only on the semantic score (SEM) of the BAMS Semantic Memory
Battery, ${ }^{26}$ to avoid the overlap of conceptualization and fluency tasks that also exist in the global cognition scores and to ensure the score is less influenced by the executive factor. The SEM score is composed of naming, general knowledge, and word definition tasks. The BAMS is a semantic battery designed to have a lower education effect and rely more on an everyday type of knowledge (more details of the instrument are available elsewhere ${ }^{26}$ ). We also performed two additional controls with the SEM score. Firstly, regressing by a processing speed measure and education, resulting in a residual (semantic memory score after controlling for education and processing speed [SEM-R]) that minimizes the secondary effect of education and the highest impact of age on agility. ${ }^{27,28}$ The second score of semantic memory was regressed on education and a principal axis factoring score using all other neuropsychological (episodic memory, executive function, and visuoconstruction) scores except the semantic one, resulting in a residual (semantic score after controlling for all other cognitive domains and education [SEM-RT]) that yields a more accurate semantic memory score not shared across domains, ${ }^{29}$ which also minimizes the secondary impact of education and other domains that contributes to semantic processing.

\section{Statistical analysis}

Descriptive and distribution analysis was performed according to variable type; thus, this could be taken into account for subsequent data analyses. We analyzed education, intelligence, occupation, and semantic memory as moderators for the relationship between age and global cognition. The moderated path analysis included age with the moderator and interaction specified as supports for causation of general cognition (Figure 1). The regression equation with interaction terms and mean centered predictors was used to construct the moderation model. We ran one model with one moderator per analysis to reduce statistical errors.

The independent and moderator variables had their mean centering calculated to reduce the correlation between product terms and constituent variables, in order to avoid extreme collinearity and unstable results. ${ }^{30} \mathrm{We}$ also decided on centering because the predictors would never be 0 in this study, allowing the intercept to have a real mean. To correct for a non-normal outcome, we used

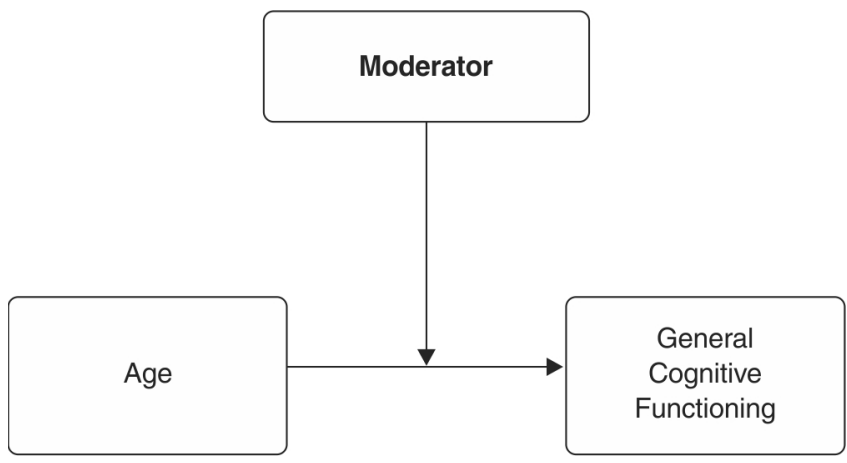

Figure 1 Moderated path analysis diagram. 
the maximum likelihood estimator (MLE) with robust standard errors and corrected model test statistics from the Satorra-Bentler model. ${ }^{30}$ The analyses were performed using SPSS version 23 and Mplus version 7.31.

\section{Results}

Table 1 displays sample characteristics and cognitive scores. As expected, age alone was a predictor of global cognitive scores (Table 2). Despite each having a significant direct relation to global cognition, neither education, nor intelligence, nor occupation were moderators for the age-global cognition relationship.

SEM-R was a significant moderator, reducing the effect of age on general cognition (Table 2, Figure 2). The effect size was small for the moderation effect for low age when comparing low and high semantic $(d=-0.151)$ and for high

Table 1 Sample characteristics

\begin{tabular}{lc}
\hline & Mean (SD) \\
\hline Age, years* & $72.69(8.25)$ \\
Education, years ${ }^{\dagger}$ & $7.78(5.50)$ \\
Dementia Ratting Scale & $131.23(9.11)$ \\
Frontal Assessment Battery & $14.22(2.77)$ \\
Vocabulary WAIS-III subtest & $30.49(12.32)$ \\
Raven's Progressive Matrices & $22.79(7.01)$ \\
Semantic score of the Semantic & $53.02(8.07)$ \\
$\quad$ Memory Battery & $\mathbf{n ~ ( \% )}$ \\
\hline & $86(75.4)$ \\
\hline Sex (female) & $80(70.2)$ \\
\hline Occupation (low-level) &
\end{tabular}

All cognitive measures are reported as raw scores.

$\mathrm{SD}=$ standard deviation .

* Min-max: 60-98; Kolmogorov-Smirnov: $p=0.004$

Min-max: 0-26; Kolmogorov-Smirnov: $p<0.001$.

$\ddagger$ Chi-square: $p<0.001$. age when comparing low and high semantic $(d=-0.134)$. The SEM after controlling for all other cognitive domains and education (SEM-RT) revealed only a trend towards significance as a moderator $(p=0.091)$.

\section{Discussion}

This work explored the role of education, intelligence, occupation, and semantic memory in moderating the effects of age on general cognition. The results support the role of semantic memory as a resilience factor and unexpectedly found that education, intelligence, and occupation did not have moderating effects in this specific sample.

Crystallized cognitive measures from language and semantic memory are widely used as resilience factors for aging. ${ }^{31,32}$ The social environment is an essential source of cultural knowledge that also builds semantic memory. Most previous studies that used vocabulary or general information measures did not control for secondary effects of education on semantic memory, but instead considered the shared covariance among measures. ${ }^{5,33}$ Our results indicate that a measure constructed as a combination of semantic memory tasks (including naming, general knowledge, and word definition) that considered the effect of education and other cognitive influences might be a valid alternative to traditional resilience factors.

Daily knowledge engagement can enhance the semantic memory of populations with sociocultural particularities. ${ }^{14}$ The acquisition and progressive differentiation of a semantic network may allow the brain to refine its connectivity, as shown by the impact of traditional education, even if in a more straightforward mechanism. ${ }^{34}$ This crystallized ability attained during one's lifetime minimizes the impact of age on cognitive performance, suggesting that it is a better proxy for cognitive changes

Table 2 Moderated path analysis for interactions between age and resilience measures

\begin{tabular}{|c|c|c|c|c|c|c|}
\hline \multirow{2}{*}{$\begin{array}{l}\text { Variables } \\
\text { Age }\end{array}$} & \multirow{2}{*}{$\frac{b *}{-0.266}$} & \multirow{2}{*}{$\frac{\mathrm{SE} \mathrm{b}^{*}}{0.078}$} & \multicolumn{2}{|c|}{$95 \% \mathrm{Cl}$} & \multirow{2}{*}{$\begin{array}{l}\text { p-value } \\
<0.001\end{array}$} & \multirow{2}{*}{$\frac{R^{2}(\%)}{14.60}$} \\
\hline & & & -0.420 & -0.112 & & \\
\hline $\begin{array}{l}\text { Age } \\
\text { Education } \\
\text { Age } \times \text { education }\end{array}$ & $\begin{array}{l}-0.193 \\
0.561 \\
-0.002\end{array}$ & $\begin{array}{l}0.074 \\
0.078 \\
0.012\end{array}$ & $\begin{array}{l}-0.338 \\
0.409 \\
-0.024\end{array}$ & $\begin{array}{l}-0.047 \\
0.714 \\
0.021\end{array}$ & $\begin{array}{c}0.009 \\
<0.001 \\
0.891\end{array}$ & 43.30 \\
\hline $\begin{array}{l}\text { Age } \\
\text { Intelligence } \\
\text { Age } \times \text { intelligence }\end{array}$ & $\begin{array}{l}-0.143 \\
3.874 \\
0.084\end{array}$ & $\begin{array}{l}0.056 \\
0.375 \\
0.066\end{array}$ & $\begin{array}{c}-0.254 \\
3.138 \\
-0.045\end{array}$ & $\begin{array}{l}-0.032 \\
4.490 \\
0.192\end{array}$ & $\begin{array}{c}0.011 \\
<0.001 \\
0.204\end{array}$ & 58.80 \\
\hline $\begin{array}{l}\text { Age } \\
\text { Occupation } \\
\text { Age } \times \text { occupation }\end{array}$ & $\begin{array}{l}-0.245 \\
2.499 \\
0.060\end{array}$ & $\begin{array}{l}0.069 \\
0.411 \\
0.058\end{array}$ & $\begin{array}{c}-0.381 \\
1.694 \\
-0.053\end{array}$ & $\begin{array}{c}-0.109 \\
3.304 \\
0.174\end{array}$ & $\begin{array}{c}<0.001 \\
<0.001 \\
0.300\end{array}$ & 29.4 \\
\hline $\begin{array}{l}\text { Age } \\
\text { SEM-R } \\
\text { Age } \times \text { SEM-R }\end{array}$ & $\begin{array}{l}-0.245 \\
0.400 \\
-0.023\end{array}$ & $\begin{array}{l}0.084 \\
0.081 \\
0.008\end{array}$ & $\begin{array}{l}-0.410 \\
0.242 \\
-0.040\end{array}$ & $\begin{array}{c}-0.081 \\
0.558 \\
-0.006\end{array}$ & $\begin{array}{c}0.003 \\
<0.001 \\
0.007\end{array}$ & 31.30 \\
\hline $\begin{array}{l}\text { Age } \\
\text { SEM-RT } \\
\text { Age } \times \text { SEM-RT }\end{array}$ & $\begin{array}{l}-0.213 \\
4.017 \\
-0.271\end{array}$ & $\begin{array}{l}0.058 \\
1.301 \\
0.161\end{array}$ & $\begin{array}{c}-0.327 \\
1.467 \\
-0.586\end{array}$ & $\begin{array}{c}-0.099 \\
6.567 \\
0.044\end{array}$ & $\begin{array}{c}<0.001 \\
0.002 \\
0.091\end{array}$ & 22.00 \\
\hline
\end{tabular}

$95 \% \mathrm{Cl}=95 \%$ confidence interval; SEM-R = semantic memory score after controlling for education and processing speed; SEM-RT = semantic score after controlling for all other cognitive domains and education.

* Unstandardized coefficients. 


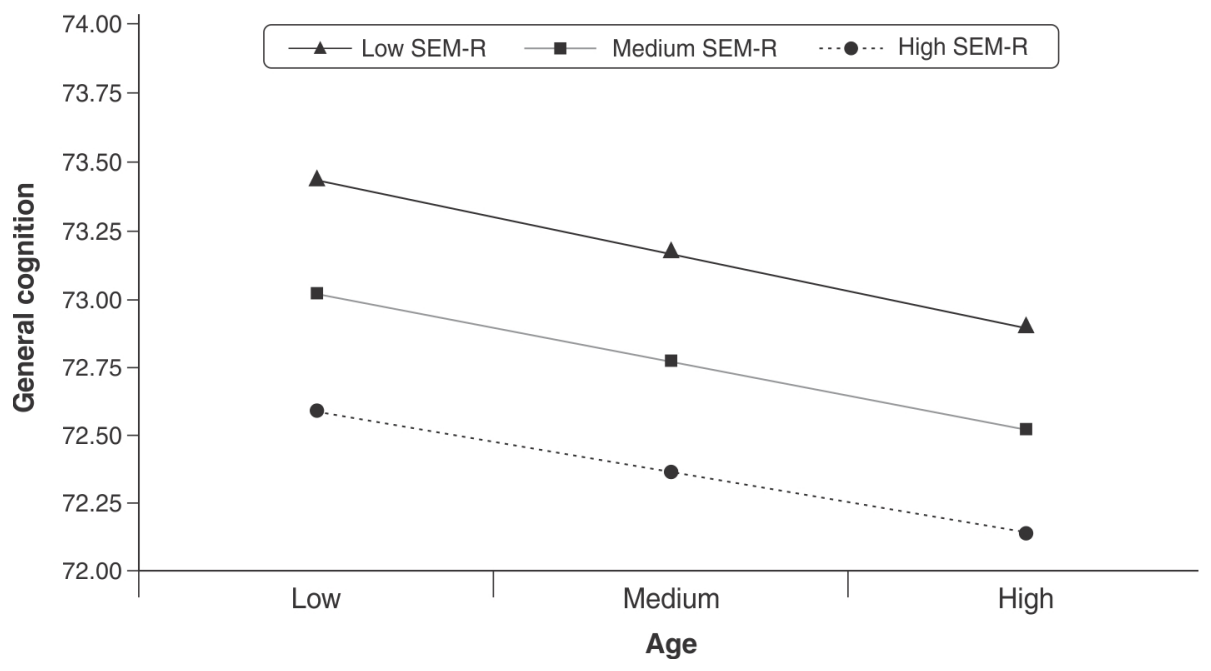

Figure 2 Moderation effect of measuring residual semantic memory of processing speed and education (semantic memory score after controlling for education and processing speed [SEM-R]) on the effect of age on general cognition. Age and SEM-R were divided into low, medium, and high, respecting one standard deviation (SD) from the mean. The Y-axis reflects the general cognition value estimated according to the interaction.

during life that can sustain and promote resilience mechanisms. Darby et al., in a similar line, found that cognitive reserve might be related to the abilities of executive function and semantic memory to sustain cognitive performance in the face of Alzheimer's disease pathology. ${ }^{35}$

The absence of educational influence is not a common finding, but it has been reported. ${ }^{36}$ In our scenario, the years of educational attainment superficially reflect the cognitive impact of this process because literacy levels do not fully correspond to what would be expected. ${ }^{10}$ Even though literacy has been reported as a stronger predictor of cognitive functioning in these situations, ${ }^{37-39}$ even reducing disparities, ${ }^{9}$ we did not have a full sample literacy assessment to include in the model.

Our findings also did not reveal a moderating effect for intelligence or occupational profile. Socioeconomic status is an important marker of opportunity, and the majority of Brazilian older adults in this sample had been engaged in low- to medium-skilled occupations, based on their environmental requirements. This particularity may obscure the occupational impact on cognition for our sample, not accurately reflecting the opportunity to improve cognitive processes through professional skills. Our sample had a great range of educational attainment even within occupational groups, but most of our participants had performed low-skilled labor throughout their lives (data not shown).

In situations featuring low socioeconomic status, intelligence may show greater variance due to environmental effect. This effect seems to evolve both chronic/stable and acute/state results, since poverty is related to cognitive depletion. ${ }^{40}$ It is possible that, for these older adults, childhood was marked by less access to books and reading, less responsive parents who were less engaged in school activities, and living in more disadvantaged environments which prevented them from reaching their intelligence potential. ${ }^{41}$ Since intelligence is stable across most human development, it is possible that this measure still reflects the socioeconomic disparities, and its impact is thus obscured in this environment.

One limitation of this study is the small cross-sectional sample size. Future work with larger samples may shed greater light upon the role of semantic memory moderation effects when controlling for all other cognitive abilities. As cross-sectional analyses cannot prove causal relationships, only provide evidence in support of causation, future models should be performed in longitudinal data considering the rate of cognitive change. We also highlight the necessity of working with multiple-indicator methods ${ }^{33}$ to clarify the extent to which semantic memory is relevant.

This study uncovers a potential limitation in using traditional resilience factors in societies with sociocultural and economic particularities. In developing countries, the use of resilience factors for aging effects based only on years of schooling may be misleading. Sociocultural issues influence educational systems and individual achievements; consequently, knowledge acquired during life moderates the effects of age on general cognition. Concomitantly, the semantic memory moderation effect should encourage studies of intervention aimed at promoting resilience factors in similar populations.

\section{Disclosure}

The authors report no conflicts of interest.

\section{References}

1 Ferri C, Prince M, Brayne C, Brodaty H, Fratiglioni L, Ganguli M, et al. Global prevalence of dementia: a Delphi consensus study. Lancet. 2005;366:2112-7.

2 Bottino CM, Azevedo D Jr, Tatsch M, Hototian SR, Moscoso MA, Folquitto $\mathrm{J}$, et al. Estimate of dementia prevalence in a community sample from São Paulo, Brazil. Dement Geriatr Cogn Disord. 2008; 26:291-9. 
3 Nitrini R, Bottino CM, Albala C, Custodio Capuñay NS, Ketzoian C, Llibre Rodriguez JJ, et al. Prevalence of dementia in Latin America: a collaborative study of population-based cohorts. Int Psychogeriatr. 2009;21:622-30.

4 Meng X, D'Arcy C. Education and dementia in the context of the cognitive reserve hypothesis: a systematic review with meta-analyses and qualitative analyses. PLoS One. 2012;7:e38268.

5 Steffener J, Barulli D, Habeck C, O'Shea D, Razlighi Q, Stern Y. The role of education and verbal abilities in altering the effect of age-related gray matter differences on cognition. PLoS One. 2014;9:e91196.

6 Stern Y. What is cognitive reserve? Theory and research application of the reserve concept. J Int Neuropsychol Soc. 2002;8:448-60.

7 Glymour MM, Manly JJ. Lifecourse social conditions and racial and ethnic patterns of cognitive aging. Neuropsychol Rev. 2008;18:223-54.

8 Manly JJ, Jacobs DM, Sano M, Bell K, Merchant CA, Small SA, et al. Effect of literacy on neuropsychological test performance in nondemented, education-matched elders. J Int Neuropsychol Soc. 1999;5:191-202.

9 Sisco S, Gross AL, Shih RA, Sachs BC, Glymour MM, Bangen KJ, et al. The role of early-life educational quality and literacy in explaining racial disparities in cognition in late life. J Gerontol B Psychol Sci Soc Sci. 2013;70:557-67.

10 Instituto Paulo Montenegro, Ação Social do IBOPE, Ação Educativa. Indicador De Alfabetismo Funcional (INAF): Estudo especial sobre alfabetismo e mundo do trabalho [Internet]. 2016 May [cited 2019 Jan 22]. acaoeducativa.org.br/wp-content/uploads/2016/09/INAFEs tudosEspeciais_2016_Letramento_e_Mundo_do_Trabalho.pdf

11 D'Aniello GE, Castelnuovo G, Scarpina F. Could cognitive estimation ability be a measure of cognitive reserve? Front Psychol. 2015;6:608.

12 Stern Y. Cognitive reserve in ageing and Alzheimer's disease. Lancet Neurol. 2012;11:1006-12.

13 Patterson K, Nestor PJ, Rogers TT. Where do you know what you know? The representation of semantic knowledge in the human brain. Nat Rev Neurosci. 2007;8:976-87.

14 Soubelet A. Engaging in cultural activities compensates for educational differences in cognitive abilities. Neuropsychol Dev Cogn B Aging Neuropsychol Cogn. 2011;18:516-26.

15 Pool LR, Weuve J, Wilson RS, Bültmann U, Evans DA, Mendes De Leon CF. Occupational cognitive requirements and late-life cognitive aging. Neurology. 2016;86:1386-92.

16 Tucker AM, Stern Y. Cognitive reserve in aging. Curr Alzheimer Res. 2011;8:354-60.

17 Steffener J, Stern Y. Exploring the neural basis of cognitive reserve in aging. Biochim Biophys Acta. 2012;1822:467-73.

18 Foss MP, de Carvalho VA, Machado TH, Dos Reis GC, Tumas V, Caramelli $P$, et al. Mattis dementia rating scale (DRS): normative data for the Brazilian middle-age and elderly populations. Dement Neuropsychol. 2013;7:374-9.

19 Beato RG, Nitrini R, Formigoni AP, Caramelli P. Brazilian version of the Frontal assessment battery $(F A B)$ : preliminary data on administration to healthy elderly. Dement Neuropsychol. 2007;1:59-65.

20 Nascimento E. WAIS-III: Escala de inteligência Wechsler para adultos - manual técnico. São Paulo: Casa do Psicólogo; 2005.

21 Angelini AL, Alves ICB, Custódio EM, Duarte WF, Duarte JLM. Matrizes progressivas coloridas de Raven: escala especial - manual. São Paulo: CETEPP;1999.

22 Brasil, Ministério do Trabalho e Emprego (MTE). Classificação Brasileira de Ocupações: Códigos, títulos e descrições [Internet]. 2010 [cited 2019 Jan 22]. www.cofen.gov.br/wp-content/uploads/2015/12/ CLASSIFICA\%C3\%87\%C3\%830-BRASILEIRA-DE-OCUPA\%C3\% $87 \%$ C3\%95ES-MEC.pdf.
23 Malloy-Diniz LF, Lasmar VA, Gazinelli Lde S, Fuentes D, Salgado JV. The Rey auditory-verbal learning test: applicability for the Brazilian elderly population. Braz J Psychiatry. 2007;29:324-9.

24 de Paula JJ, Ávila RT, Costa DS, Moraes EN, Bicalho MA, Nicolato $\mathrm{R}$, et al. Assessing processing speed and executive functions in low educated older adults: the use of the five digit test in patients with Alzheimer's disease, mild cognitive impairment and major depressive disorder. Clin Neuropsychiatry. 2011;8:339-46.

25 de Paula JJ, Costa MV, de Andrade GF, Ávila RT, Malloy-Diniz LF. Validity and reliability of a "simplified" version of the Taylor complex figure test for the assessment of older adults with low formal education. Dement Neuropsychol. 2016;10:52-7.

26 Bertola L, Malloy-Diniz LF. Assessing knowledge: psychometric properties of the BAMS semantic memory battery. Arch Clin Psychiatry (São Paulo). 2018;45:33-7.

27 Finkel D, Reynolds CA, McArdle JJ, Pedersen NL. The longitudinal relationship between processing speed and cognitive ability: genetic and environmental influences. Behav Genet. 2005;35:535-49.

28 Salthouse TA. Selective review of cognitive aging. J Int Neuropsychol Soc. 2010;16:754-60

29 Salthouse TA. Shared and unique influences on age-related cognitive change. Neuropsychology. 2017;31:11-9.

30 Kline RB. Principles and practice of structural equation modeling. 3rd ed. New York: The Guilford; 2011.

31 Scarmeas N, Stern Y. Cognitive reserve: implications for diagnosis and prevention of Alzheimer's disease. Curr Neurol Neurosci Rep. 2004; 4:374-80.

32 Siedlecki KL, Stern Y, Reuben A, Sacco RL, Elkind MS V, Wright CB. Construct validity of cognitive reserve in a multiethnic cohort: the northern Manhattan study. J Int Neuropsychol Soc. 2009;15: 558-69.

33 Jones RN, Manly J, Glymour MM, Rentz DM, Jefferson AL, Stern Y. Conceptual and measurement challenges in research on cognitive reserve. J Int Neuropsychol Soc. 2011;17:593-601.

34 Dehaene S, Cohen L, Morais J, Kolinsky R. Illiterate to literate: behavioural and cerebral changes induced by reading acquisition. Nat Rev Neurosci. 2015;16:234-44.

35 Darby RR, Brickhouse M, Wolk DA, Dickerson BC; Alzheimer's Disease Neuroimaging Initiative. Effects of cognitive reserve depend on executive and semantic demands of the task. J Neurol Neurosurg Psychiatry. 2017;88:794-802.

36 O'Connor DW, Pollitt PA, Treasure FP. The influence of education and social class on the diagnosis of dementia in a community population. Psychol Med. 1991;21:219-24.

37 Dotson VM, Kitner-Triolo MH, Evans MK, Zonderman AB. Effects of race and socioeconomic status on the relative influence of education and literacy on cognitive functioning. J Int Neuropsychol Soc. 2009; 15:580-9.

38 Manly JJ, Jacobs DM, Touradji P, Small SA, Stern Y. Reading level attenuates differences in neuropsychological test performance between African American and white elders. J Int Neuropsychol Soc. 2002;8:341-8.

39 Manly JJ, Touradji P, Tang M, Stern Y. Literacy and memory decline among ethnically diverse elders. J Clin Exp Neuropsychol. 2003; 25:680-90.

40 Mani A, Mullainathan S, Shafir E, Zhao J. Poverty impedes cognitive function. Science. 2013;341:976-80.

41 Hanscombe KB, Trzaskowski M, Haworth CM, Davis OS, Dale PS, Plomin R. Socioeconomic status (SES) and children's intelligence (IQ): In a uk-representative sample SES moderates the environmental, not genetic, effect on IQ. PLoS One. 2012;7:e30320. 